\title{
Modulation of intracortical facilitatory circuits of the human primary motor cortex by digital nerve stimulation
}

\author{
Simone Zittel · Tobias Bäumer · Joachim Liepert
}

Published online: 13 October 2006

(C) Springer-Verlag 2006

\section{Erratum to: Exp Brain Res \\ DOI 10.1007/s00221-006-0624-2}

In Table 1, Experiment 2, ICF condition stimulus intensity $75 \%$, the value for the Test-MEP amplitude should read:

$0.48 \mathrm{mV}( \pm 0.12)$ not $0.30 \mathrm{mV}( \pm 0.12)$

The online version of the original article can be found at http://dx.doi.org/10.1007/s00221-006-0624-2

S. Zittel $(\bowtie) \cdot$ T. Bäumer $\cdot$ J. Liepert

Department of Neurology,

University Medical Center Eppendorf,

Martinistr 52, 20246 Hamburg, Germany

e-mail: szittel@uke.uni-hamburg.de 